\title{
Probabilistic approach to rock fall hazard assessment: potential of historical data analysis
}

\author{
C. Dussauge-Peisser ${ }^{1}$, A. Helmstetter ${ }^{2}$, J.-R. Grasso ${ }^{2}$, D. Hantz ${ }^{1}$, P. Desvarreux ${ }^{1}$, M. Jeannin ${ }^{1}$, and A. Giraud ${ }^{1}$ \\ ${ }^{1}$ Laboratoire Interdisciplinaire de Recherche Impliquant la Géologie et la Mécanique, Université Joseph Fourier, BP53, 38041 \\ Grenoble cedex 9, France \\ ${ }^{2}$ Laboratoire de Géophysique Interne et Tectonophysique, BP53, 38041 Grenoble cedex 9, France
}

Received: 19 October 2001 - Revised: 18 January 2002 - Accepted: 21 January 2002

\begin{abstract}
We study the rock fall volume distribution for three rock fall inventories and we fit the observed data by a power-law distribution, which has recently been proposed to describe landslide and rock fall volume distributions, and is also observed for many other natural phenomena, such as volcanic eruptions or earthquakes. We use these statistical distributions of past events to estimate rock fall occurrence rates on the studied areas. It is an alternative to deterministic approaches, which have not proved successful in predicting individual rock falls. The first one concerns calcareous cliffs around Grenoble, French Alps, from 1935 to 1995. The second data set is gathered during the 1912-1992 time window in Yosemite Valley, USA, in granite cliffs. The third one covers the 1954-1976 period in the Arly gorges, French Alps, with metamorphic and sedimentary rocks.
\end{abstract}

For the three data sets, we find a good agreement between the observed volume distributions and a fit by a power-law distribution for volumes larger than $50 \mathrm{~m}^{3}$, or $20 \mathrm{~m}^{3}$ for the Arly gorges. We obtain similar values of the $b$ exponent close to 0.45 for the 3 data sets. In agreement with previous studies, this suggests, that the $b$ value is not dependant on the geological settings. Regarding the rate of rock fall activity, determined as the number of rock fall events with volume larger than $1 \mathrm{~m}^{3}$ per year, we find a large variability from one site to the other. The rock fall activity, as part of a local erosion rate, is thus spatially dependent.

We discuss the implications of these observations for the rock fall hazard evaluation. First, assuming that the volume distributions are temporally stable, a complete rock fall inventory allows for the prediction of recurrence rates for future events of a given volume in the range of the observed historical data. Second, assuming that the observed volume distribution follows a power-law distribution without cutoff at small or large scales, we can extrapolate these predictions to events smaller or larger than those reported in the data sets. Finally, we discuss the possible biases induced by the

Correspondence to: C. Dussauge-Peisser

(carine.dussauge@ujf-grenoble.fr) poor quality of the rock fall inventories, and the sensibility of the extrapolated predictions to variations in the parameters of the power law.

\section{Introduction}

Among many natural hazards, rock falls are very frequent in mountain areas. The word "rock falls" is usually used to describe small phenomena, from block falls of a few $\mathrm{dm}^{3}$ up to $10000 \mathrm{~m}^{3}$ events. "Rockslides" often involve more than $100000 \mathrm{~m}^{3}$ and "rock avalanches" can reach several million cubic meters. In the following text, we will only use the word "rock falls" without any volume distinction. Rock falls are always rapid phenomena, difficult to predict without any extensive instrumentation (see, for example, Erisman and Abele, 2001). Since more urbanisation is developing in rock fall prone areas, there is a growing need for hazard assessment. As for landslides, floods, earthquakes or volcanic eruptions, evaluating rock fall hazard means estimating the location, size and probability of occurrence in a given time period of potential events, and then their propagation. The risk evaluation also includes the potential impact on vulnerable infrastructures. The propagation processes have been extensively studied and many models are available. Here we focus on the occurrence of the phenomena in the space and time domains. 1) The location and size of potential rock falls are mainly dictated by the geometrical patterns and geomechanical properties of the rock mass, with the strongest influence of existing discontinuities. Detailed field work based on geomechanical and expert analysis leads to the characterisation of some specific instabilities. However, for studies of natural cliffs, this approach is bound by a lack of feasibility to know extensively the geomechanical patterns of the whole area to be studied (commonly several kilometres of cliffs). Statistical analysis then appears as a suitable alternative to deterministic mechanics approaches. 2) Regarding the temporal occurrence of such phenomena, the prevision in time can only be feasible over a short-term period (a few months 
(a)

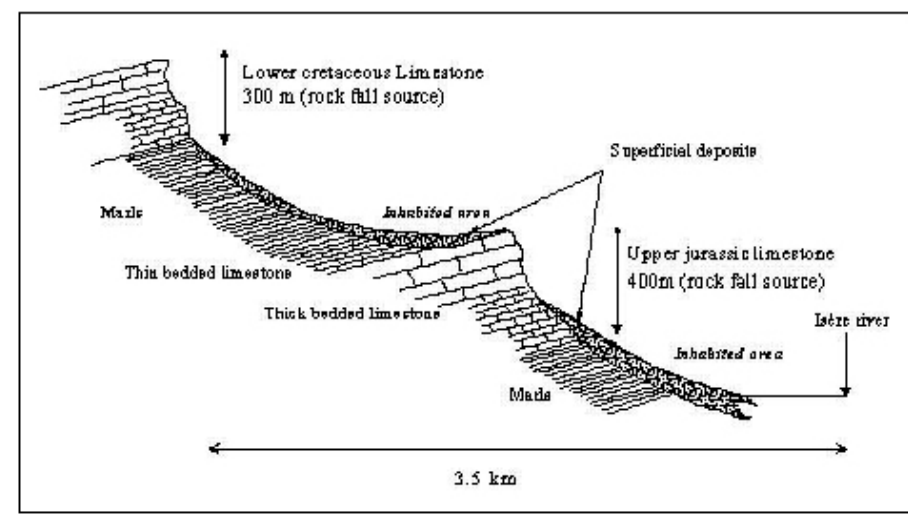

(b)

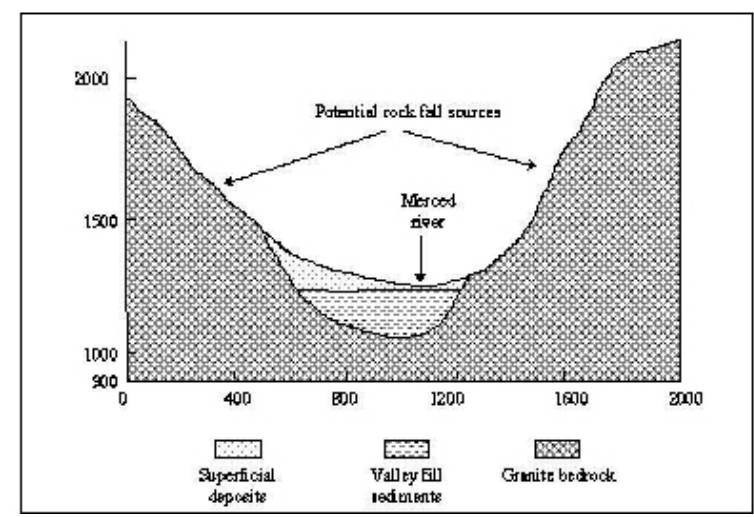

Fig. 1. Typical cross section of the cliffs concerned by the rock fall inventories. (a) Sub-vertical calcareous cliffs from the Chartreuse massif, Grenoble, France. Two main limestone levels are separated by a marly level. (b) Granitic cliffs from the Yosemite Valley, California, USA (scales in meter). The valley fill sediments consist of deltaic and lacustrine sediments, whereas the superficial deposits consist of rock fall and rock slide talus (after Wieczorek and Jäger (1996), with permission).

to a few days) if the unstable slope is well instrumented and the movement follows specific processes (e.g. Azimi, 1996). In most cases no instrumentation is available. Long-term predictions (a few years, a few decades or a few centuries) are only qualitatively estimated on the basis of the experience of an expert (e.g. Cancelli and Crosta, 1993; Hoek, 1998; Rouiller et al., 1998; Mazzoccola and Sciesa, 2000). The temporal evaluation appears to be the weakest point of rock fall hazard studies.

In other natural hazard fields, such as floods or earthquakes, distribution laws have been proposed, based on statistical analysis of historical data sets, to be representative for the observed frequency-size distribution of events. These laws, exponential-like for floods (e.g. Guillot and Duband, 1967; Water Resources Council, 1982) or power laws for earthquakes (Gutenberg and Richter, 1949), are widely used to derive a probabilistic recurrence rate of an event of a given size. More recently, this statistical approach has been applied to landslides, with their surface distribution being well fitted by a power law (e.g. Hovius et al., 1997; Blodgett et al., 1996). This method allows for the calculation of erosion rates, as well as the probability of occurrence of a landslide of a given size. Some studies have shown that the volume distributions of rock falls from limited homogeneous areas are well fitted by a power law (Hungr et al., 1999 and refer- ences therein; Dussauge et al., 2001). Due to the low number of available data sets, such studies are still rare.

We present the results of statistical analysis for 3 rock fall inventories, pointing out the possible biases when applied to hazard estimates. When comparing our observed volume distributions to other ones proposed in the literature, common features appear, such as the shape of the law - a power law in all cases - and the exponent of this law. Then we discuss the opportunity to use this distribution law as a new tool for temporal hazard assessment. Several questions are raised about the validity of the law in both space and time domains. We point out the possibilities and limits of such an approach in the rock fall field, which still needs to be developed in order to answer the requirements of risk managers.

\section{Statistical analysis of three rock fall inventories}

\subsection{Characteristics of rock fall inventories}

Natural rock falls can be defined as events occurring on natural cliffs - no road or mine cuts - and triggered without any human intervention. For such events, the data collection suffers from two main problems linked to eachother. First, very few extensive data sets up to now are available. The existing ones concern road or railway cuts rather than 
Table 1. Characteristics of some rock fall volumes distributions

\begin{tabular}{|c|c|c|c|c|c|c|c|}
\hline References & Site & $\begin{array}{l}\text { Geological } \\
\text { setting }\end{array}$ & $\begin{array}{l}\text { Number } \\
\text { of events }\end{array}$ & $\begin{array}{c}\text { Time } \\
\text { window }\end{array}$ & $\begin{array}{l}\text { Sampled } \\
\text { volumes } \\
\left(\mathrm{m}^{3}\right)\end{array}$ & $\begin{array}{l}\text { Range of the } \\
\text { power law fit } \\
\qquad\left(\mathrm{m}^{3}\right)\end{array}$ & Exponent $\mathrm{b}^{\mathrm{a}}$ \\
\hline Gardner, 1970 & $\begin{array}{l}\text { Alberta, Canada, } \\
\text { natural cliffs }\end{array}$ & $\begin{array}{c}\text { Calcareous } \\
\text { and quartzitic rock }\end{array}$ & 409 & $\begin{array}{l}2 \text { summer } \\
\text { periods }\end{array}$ & $10^{-6}-10$ & $10^{-2}-10$ & 0.72 \\
\hline $\begin{array}{l}\text { Our study, data } \\
\text { from Jeannin } \\
(2001)\end{array}$ & $\begin{array}{l}\text { Upper Arly gorges, } \\
\text { French Alps }\end{array}$ & $\begin{array}{l}\text { Metamorphic and } \\
\text { sedimentary rocks }\end{array}$ & 59 & 22 years & $5-10^{4}$ & $20-3000$ & $0.45 \pm 0.15$ \\
\hline $\begin{array}{l}\text { Our study, data } \\
\text { from RTM } \\
\text { (1996) }\end{array}$ & $\begin{array}{c}\text { Grenoble, French } \\
\text { Alps }\end{array}$ & $\begin{array}{l}\text { Calcareous } \\
\text { cliffs }\end{array}$ & 87 & 60 years & $0.5-10^{6}$ & $50-10^{6}$ & $0.41 \pm 0.11$ \\
\hline $\begin{array}{l}\text { Our study, data } \\
\text { from Wieczoreck } \\
\text { et al. (1992) }\end{array}$ & $\begin{array}{c}\text { Yosemite Valley, } \\
\text { California }\end{array}$ & Granitic cliffs & 101 & 78 years & $1-10^{6}$ & $50-10^{6}$ & $0.46 \pm 0.11$ \\
\hline $\begin{array}{c}\text { Dussauge et al. } \\
\text { (2001) }\end{array}$ & World wide & $\begin{array}{l}\text { Undifferentiated } \\
\text { rock cliffs }\end{array}$ & 142 & $\begin{array}{l}10000 \\
\text { years }\end{array}$ & $10^{3}-2.10^{10}$ & $3.10^{7}-2.10^{10}$ & 0.52 \\
\hline \multirow{2}{*}{$\begin{array}{c}\text { Hungr et al. } \\
\text { (1999) }\end{array}$} & $\begin{array}{c}\text { British Columbia } \\
\text { Canada }\end{array}$ & $\begin{array}{l}\text { Massive felsic } \\
\text { rock }\end{array}$ & $\begin{array}{l}389^{\mathrm{b}, 1} \\
123^{\mathrm{b}, 2}\end{array}$ & $\begin{array}{l}30 \text { years } \\
13 \text { years }\end{array}$ & $\begin{array}{l}10^{-2}-10^{8} \\
10^{-2}-10^{8}\end{array}$ & $\begin{array}{c}10^{-2}-10^{4} \\
1-10^{4}\end{array}$ & $\begin{array}{l}0.43 \\
0.40\end{array}$ \\
\hline & Road cuts & $\begin{array}{l}\text { Jointed } \\
\text { metamorphic } \\
\text { rock }\end{array}$ & $\begin{array}{c}64^{\mathrm{b}, 3} \\
122^{\mathrm{b}, 4}\end{array}$ & $\begin{array}{c}- \\
22 \text { years }\end{array}$ & $\begin{array}{l}10^{-2}-10^{8} \\
10^{-2}-10^{8}\end{array}$ & $\begin{array}{l}1-10^{4} \\
1-10^{4}\end{array}$ & $\begin{array}{l}0.40 \\
0.70 \\
0.65\end{array}$ \\
\hline $\begin{array}{c}\text { Rousseau } \\
\text { (1999) }\end{array}$ & $\begin{array}{c}\text { Mahaval, La } \\
\text { Réunion, French } \\
\text { Island } \\
\text { Instrumental } \\
\text { measurements }\end{array}$ & $\begin{array}{c}\text { Single natural } \\
\text { basaltic cliff }\end{array}$ & 370 & 2 months & $\begin{array}{l}\mathrm{V}_{\max }= \\
9.10^{6(\mathrm{c})}\end{array}$ & $\begin{array}{l}1.5 \text { order of } \\
\text { magnitude }\end{array}$ & 1 \\
\hline
\end{tabular}

Table 2. $\alpha$ values $\left(\mathrm{n}_{1}\right)$ and annual number of rock falls larger than $100 \mathrm{~m}^{3}, \mathrm{n}_{100}$, calculated from the power-law distribution for 3 case studies. In order to compare values from spatially different areas, the coefficients are normalised by the surface of cliffs which are sources of events

\begin{tabular}{cccccc}
\hline Site & $\begin{array}{c}\alpha=\mathrm{n}_{1} \\
\text { (number/year) }\end{array}$ & $\begin{array}{c}\mathrm{n}_{100} \\
\text { (number/year) }\end{array}$ & $\begin{array}{c}\text { Length of cliff } \\
\text { considered }(\mathrm{km})\end{array}$ & $\begin{array}{c}\text { Approximate } \\
\text { cliff surface }\left(\mathrm{km}^{2}\right)\end{array}$ & $\mathrm{n}_{100} / 10 \mathrm{~km}^{2}$ \\
\hline Grenoble area & 4.2 & 0.62 & 120 & 24 & 0.26 \\
Yosemite Valley & $18^{*}$ & 2.16 & 100 & 30 & 0.72 \\
Upper Arly gorges & 8.5 & 1.07 & 2.2 & 0.55 & $\begin{array}{c}-19.45- \\
\text { extrapolated }\end{array}$
\end{tabular}

* In the Yosemite case, for an accurate calculation of the $b$ value, the distribution law was studied only for a subset of the total data set onequarter with quantitative volume estimates (Dussauge et al., 2001). However, for the $\alpha$ coefficient, the real number of events reported in the time window must be considered. The result of the sub-distribution $(\alpha=4.5$, Fig. 2$)$ is multiplied by 4 .

natural cliffs (Hungr et al., 1999). Second, hardly any instrumental measurements exist for studying rock fall activity. Luckman (1976) already pointed out this deficiency, and as far as we know no exhaustive field work has been published since this time. Most data are collected in the field by forest guards and rangers. Other ones are simply reported in historical archives. In particular, the volumes of each event are only roughly estimated, on the basis of the scar in the cliff if possible, otherwise estimated in the deposition area. Recently, specific types of instrumentation, which initially aimed at monitoring other phenomena, such as volcanic eruptions, have been used to derive information about rock falls (Rousseau, 1999). This can be a future route to increase the number of instrumental data, but it has been seldom investigated up to now.

This statement can induce several possible biases on rock 

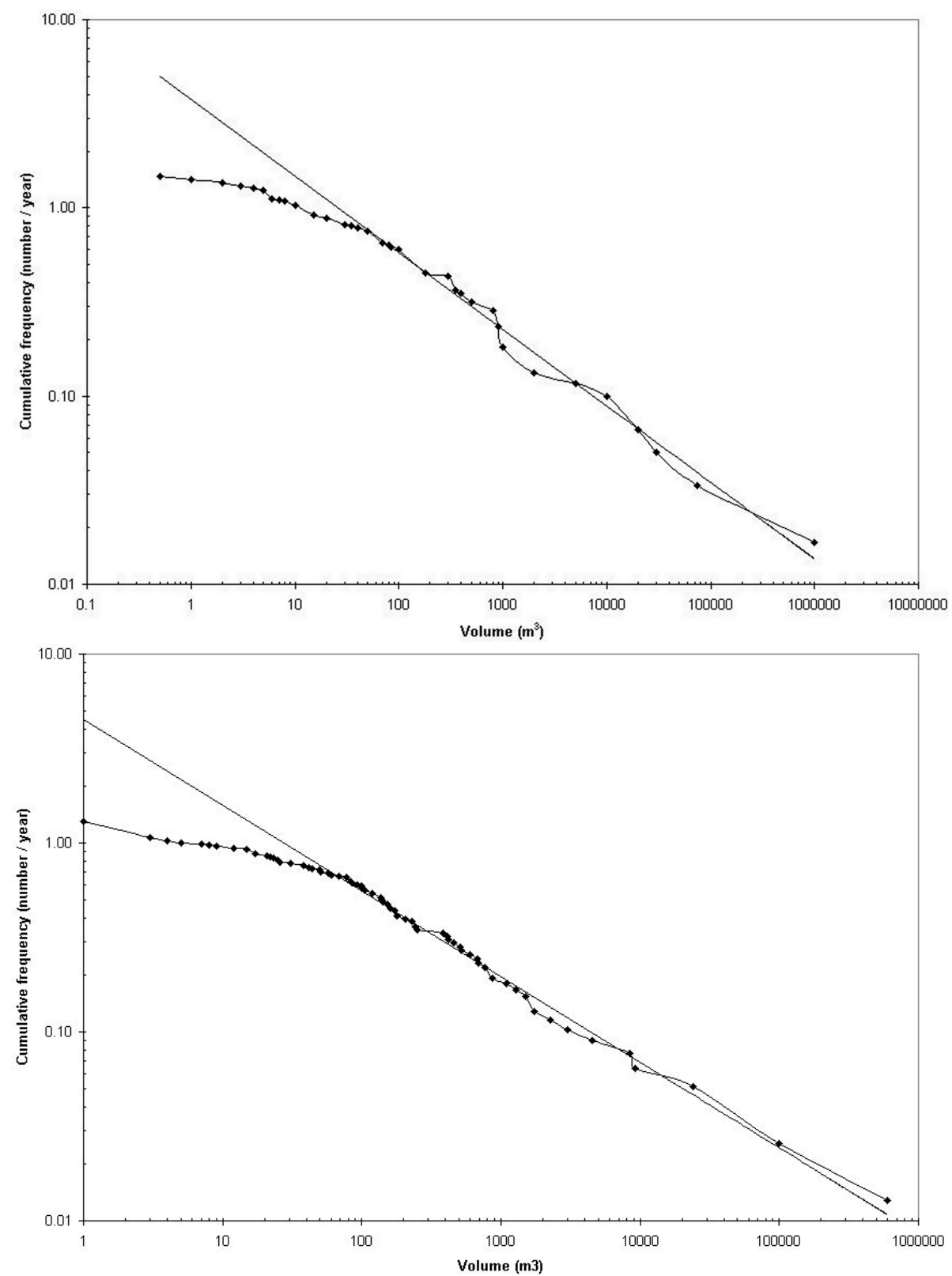

Fig. 2. Cumulative volume distributions for the rock fall records (a) Grenoble area, 87 records over $120 \mathrm{~km}$ of calcareous cliffs in the $1935-$ 1995 time window. The straight line represents the power law fit, $f=4.2 \mathrm{~V}^{-0.41}$ over the $50-10^{6} \mathrm{~m}^{3}$ volume range. (b) Yosemite Valley, 101 records with quantitative volume estimates over $100 \mathrm{~km}$ of granite cliffs, $1915-1992$. The power law is accepted over $50-10^{6} \mathrm{~m}^{3}$, with the equation $f=4.5 V^{-0.46}$. The real number of data for this area over this time window - including data with qualitative volume estimates - is four times as high as what is used for the calculation of $b=0.46$. The value $\alpha=4.5$ is thus four times as low as the real representative value.

fall data sets. In the time domain, the observation rate is not uniform. It depends on the visiting frequency of the different areas prospected, which is not always the same through the ages. For example, a rocky area may have been visited occasionally by forest guards during a century; if a road is built, the visits become daily. In the size domain, a clear underestimation of small volumes in most inventories arises from two causes. First, when dealing with old past events, only the biggest ones, which have remained in human memory, are still to be found in the archives. Second, even nowadays, rock falls are noticed mostly when they create dam- age in forests, roads, and buildings. Hence, small events are seldom reported. This last remark also applies to a certain extent to inventories gathered along road cuts, the minimum volumes under which events are underestimated are lower than for natural cliffs.

Due to these difficulties, special care must be taken to assess the statistical stability of the data sets used. In this study, the overall original inventories are restricted to a time window where the number of events per year - or decade or century - is relatively constant. 


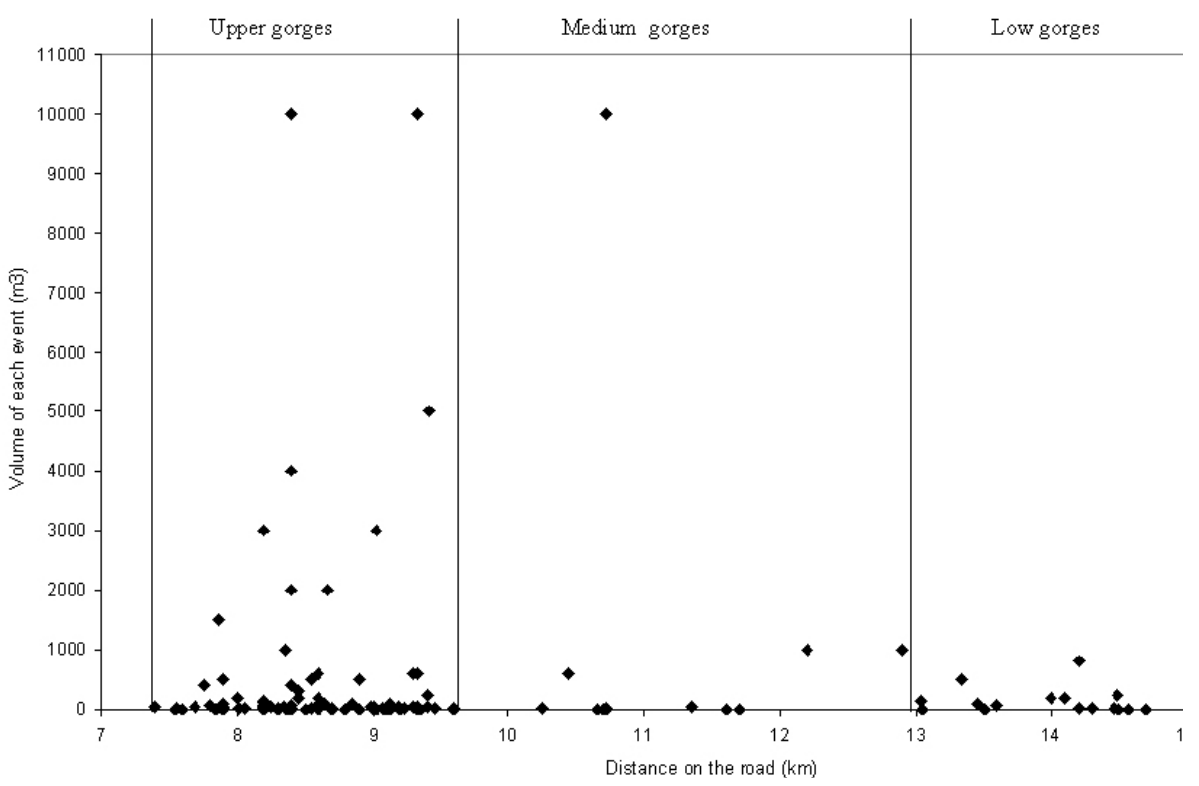

Fig. 3. Spatial distribution of the rock falls along the road 212 in the Arly gorges, Savoie, France, in the 1948-1996 period. Data from Jeannin (2001) with permission.

2.2 The Grenoble and Yosemite inventories: two regionalscale inventories

For the study of rock fall hazard assessment, we need to consider rock falls having their origin in natural cliffs, as well as on talus slopes or road cuts. We analysed two inventories with a similar time and space scale. Each one covers a large area with a series of natural rock cliffs varying in height. On each area, the geological setting can be considered as homogeneous, i.e. the lithology and fracture pattern are roughly similar at the regional scale. However, the geological setting differs from one case to the other.

The first one concerns the calcareous cliffs of the Grenoble area, French Alps. These cliffs are made of limestone and marls from the upper Jurassic and lower Cretaceous age. They represent altogether $120 \mathrm{~km}$ in length. They are 50 to $400 \mathrm{~m}$ high, with a mean value of $200 \mathrm{~m}$. The morphology is mainly sub-vertical, the stratification dips gently inward (Fig. 1a). The discontinuity sets vary slightly from one location to another, but there are mainly three sub-vertical sets, one parallel to the direction of the cliff surface, and two others crossing it. The most common rock fall mechanisms are wedge failures, initiated on these two crossing sets, tower toppling and overhang failures, where the succession of limestone and marls suffer from differential erosion.

Forest guards from the RTM office have recorded rock falls since 1850 (RTM, 1996). Since the data collection is affected by the biases discussed previously, we only consider 88 events in the 1935-1995 time window (see also Dussauge et al., 2001). Rock fall volumes range from 0.5 to $106 \mathrm{~m}^{3}$.

The second inventory is representative of the Yosemite Valley, California, USA. It covers a cumulative length of $100 \mathrm{~km}$ of massive granite cliffs from the Cretaceous age, which are up to $1000 \mathrm{~m}$ high, with a mean value of $300 \mathrm{~m}$ (Fig. 1b). These cliffs present mainly a round shape morphology, except for some steeper walls. They are characterised by an important set of discontinuities parallel to the topography. These discontinuities are responsible for a sheeting process, resulting from the release of pressure of previously buried rocks. Rock falls are partly induced by this sheeting process. The National Park rangers and USGS geologists have reported the occurrence of rock falls in the Yosemite Valley since 1850, gathering more than 400 events (Wieczorek et al., 1992). The distribution law was first tested on the whole set of data (Wieczorek et al., 1995). But among these data, only one-quarter has quantitative volume estimates. For a more accurate calculation of one parameter of the law (the $b$ value, see next section), with less biases, only 101 events with quantitative volume estimates have been taken into account (Dussauge et al., 2001). They cover the 1915-1992 period (78 years) and the $1-6.10^{5} \mathrm{~m}^{3}$ volume range.

For both inventories, rock fall volumes are primarily estimated in the deposition area. These two data sets cover an area that is geologically homogeneous. They both went through several glaciations, the last one ending about 10000 years ago (Würm in the Alps, Tioga in North America). They have been releasing from the weight of ice since this time and a few rock fall events have been triggered by earthquakes (around 10\% in Yosemite and close to 0\% in Grenoble area). The difference between the two series of cliffs is the lithology and the fracture systems, which induce different failure mechanisms for the rock falls.

For each of these data sets, we study the distribution of rock falls according to their volume. The frequency is defined as the number of events divided by the length of the time window, respectively, 60 and 78 years. Each distribu- 


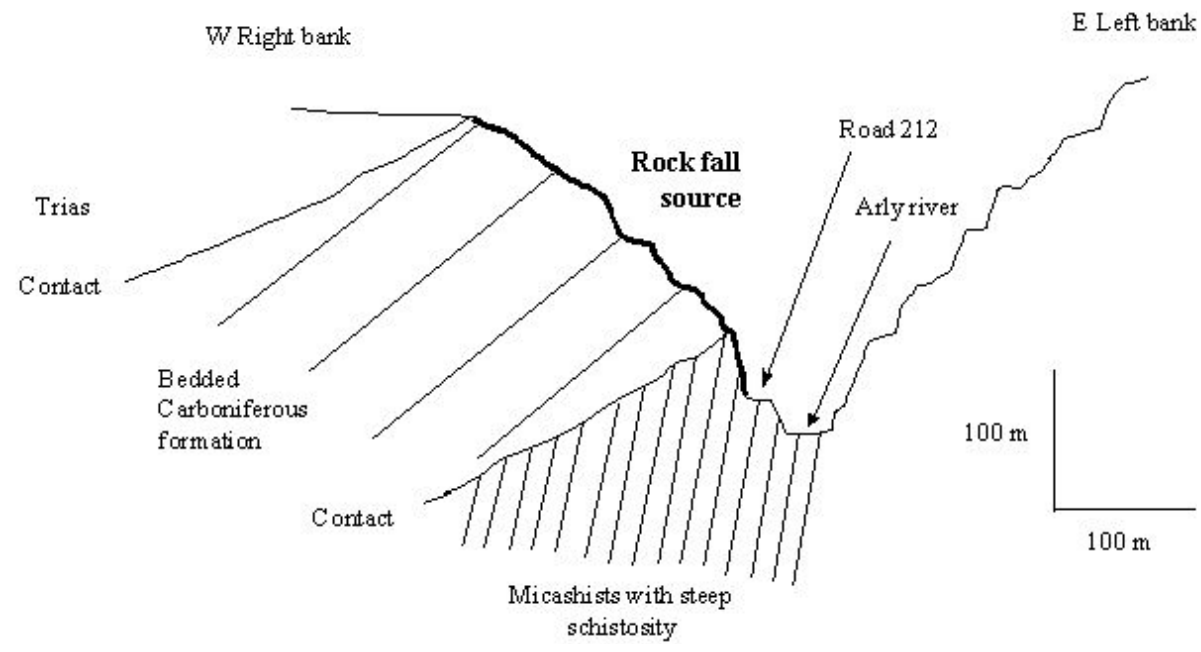

Fig. 4. Geological cross-section of the upper Arly gorges, Savoie, France. The rock fall source area is approximately $250 \mathrm{~m}$ high.

tion is statistically tested in order to find out the best fit over the wider range of volumes. Figure 2 presents the two distributions with a logarithmic scale. As described in Dussauge et al. (2001), the power-law distribution provides a good fit to the data, excluding exponential or Gumbel laws. Such a law is written

$n(V)=\alpha V^{-b}$,

where $V$ is the volume, $n(V)$ is the number of events per year with a volume greater than $V$, and $\alpha$ and $b$ are constants. Other laws with more parameters may provide a better fit, but we choose to use the minimum number of parameters, i.e. the simplest law for this first step analysis. The $b$ value can be estimated either from a linear regression method or by a maximum likelihood method. The maximum likelihood estimate for $b$ is given by Aki, 1965 .

$b=1 / \operatorname{Ln}(10)\left(<\log V>-\log V_{0}\right)$,

where $<\log (V)>$ is the average value of $\log (V)$, and $V_{0}$ is the minimum volume considered, above which the catalogue is assumed to be complete. For the two data sets, the power law is accepted by a $\chi^{2}$ test for volumes larger than $50 \mathrm{~m}^{3}$ $\left(\chi^{2}=5.2\right.$; see Dussauge et al., 2001). Under this value, the observed number of events per year is lower than the one expected from the power law. This lack of small volume compared to the theoretical law is probably due to the resolution level of the sampling technique. Therefore, we study the rock fall volume distribution above this volume $V_{0}$. To determine $V_{0}$, we test different threshold volumes, and we choose the minimum value of $V_{0}$ for which the power-law distribution is accepted by the $\chi^{2}$ test and for which the $b$ value is constant, when we increase the threshold volume above $V_{0}$. The linear regression and maximum likelihood methods provide similar values for $b$ and $\alpha$. The mean value appears in Table 1. We find similar $b$ values for the two inventories, respectively, 0.41 for the Grenoble area and 0.46 for the Yosemite catalogue. The standard deviation of the $b$ value can be estimated using a maximum likelihood method and is given by (Aki, 1965)

$\sigma=b / N^{-1 / 2}$,

where $N$ is the number of events, and $b$ is the $b$ value from Eq. (1). Using Eq. (3), the $b$ value standard deviation is equal to 0.11 for both Grenoble and Yosemite inventories. Thus, the difference between the two exponents is not statistically significant.

2.3 The Val d'Arly rock fall inventory: a local-scale inventory

In order to consider a smaller time and space scale, we study an inventory gathered in the Val d'Arly gorges, located between Ugine and Flumet, Savoie, French Alps. This example allows for the analysis of a larger number of rock falls coming from a single cliff.

The road 212 was built on the flanks of these gorges at the beginning of the century. The local road service has noticed the extensive rock fall activity over a $7 \mathrm{~km}$ distance since 1954. It has reported daily every event larger than $1 \mathrm{~m}^{3}$, where debris has fallen on the road, causing momentary road closure. This procedure prevents the data from being affected by the bias discussed in Sect. 2.1, since the events are reported daily. An analysis of the spatial distribution of these rock falls shows a high concentration of events in the upper part of the gorges over $2.2 \mathrm{~km}$ (Fig. 3). On this section, 111 rock falls, from 1 to $10000 \mathrm{~m}^{3}$, occurred from 1954 to 1994. Since protective structures, such as galleries and fences, have been built since 1976, thereby decreasing significantly the number of events, we only consider the time window from 1954-1976.

On the section considered, the rock slopes can be distinguished bt two parts, as shown in Fig. 4. The left bank of the river and the first twenty meters of the right bank are made of mica schists, characterised by a tight schistosity, 
steeply dipping west. Above these mica schists are sedimentary rocks from the Carboniferous formation. They are composed of conglomerates and an alternation of sandstone and more crumbly shale. The stratification dips generally 40 to $50^{\circ} \mathrm{W}$, that is to say inward on the right bank. The main discontinuity sets are the schistosity in the mica schists, which is very closely spaced, and the stratification in the Carboniferous formation. Three other sets of discontinuities affect both the mica schists and the Carboniferous formation and cut them into blocks (Jeannin, 2001).

Since most of the rock falls have their origin above the man-made cut, mainly in the Carboniferous formation, the influence of the road cut on the triggering of events is assumed to be weak. The main mechanism for rock falls is toppling, in the micaschists as well as in the Carboniferous formation.

In conclusion, the rock fall data gathered on the road section studied constitutes an inventory considered to be complete over 22 years. It includes 59 events occurring from a single natural cliff. The geological setting, identical over the whole area, is different from the previous cases, as well as the main rock fall mechanism.

The volume distribution of the rock falls is presented in Fig. 5. The data are well fitted by a power law in the range of $20-3000 \mathrm{~m}^{3}$. The exponent $\mathrm{b}$, calculated with a linear regression method, is equal to 0.45 , with a standard deviation of 0.15 . This value is very close to those found for the Grenoble and Yosemite inventories. It is also in accordance with the values proposed by Hungr et al. (1999) for describing the volume distributions of rock falls from different road cuts in British Columbia, Canada.

An under-sampling of the data appears once more, under $20 \mathrm{~m}^{3}$. This value is not much lower than for the two previous cases, $-50 \mathrm{~m}^{3}$. Some small volumes are stopped by the vegetation present on the slope, or they do not create much damage on the road and thus are not reported. However, if this value represents the resolution level associated with the sampling technique, it is surprising that the resolution level in this case is not much better than for the two previous cases - the minimum value for the validity of the law is not much lower than for inventories over broader areas. Also, the end of the distribution does not follow the theoretical power law, but this may be due to statistical fluctuations: the time window is too short to be statistically representative of the rock fall activity for volumes greater than $3000 \mathrm{~m}^{3}$.

The power-law distribution is still statistically accepted by the $\chi^{2}$ test, considering all volumes larger than $20 \mathrm{~m}^{3}$.

This example shows that a power law also represents the volume distribution of rock falls having their origin on a single cliff. Data from Gardner (1970), collected at the base of a single calcareous and quartzitic cliff in Alberta, Canada, during two summer periods, also show this power-law distribution for volumes ranging from $10^{-2}$ to $10 \mathrm{~m}^{3}$. In this case, the $b$ value is higher, $b=0.72$. (Hungr et al., 1999).

\section{Synthesis of the observed distribution patterns}

Looking at different rock fall inventories (Table 1), the volume distributions are fitted by a power law, at least above a given volume. In all cases, the distribution curve is flat for the smallest volumes and does not fit the power law. This is also observed for landslide size distributions. Stark and Hovius (2001) propose that this is a pure censoring effect, due to the sampling resolution, which does not challenge the overall power-law behaviour. As well, power laws observed in the seismic field suffer a flat behaviour due to the monitoring resolution (Gutenberg and Richter, 1949). In addition, the results for rock falls from our study and others, summarised in Table 1, show that this law is accepted regardless of the volume range from $0.01-10 \mathrm{~m}^{3}$ to $10^{7}-10^{10} \mathrm{~m}^{3}-$ or the period of observation - from two months to 10000 years.

Such a distribution law could result from the variability of the cliff dimensions - height in particular - on the large areas considered (this aspect is further discussed in Dussauge et al., 2001). The inventories from the Arly gorges and the Alberta cliffs (Gardner, 1970), gathered on a single cliff, prove that the distribution law is not due to such a geometrical effect, i.e. an integration process over cliffs of different heights.

Rousseau (1999) reports rock falls from a single basaltic cliff on La Réunion Island by recording the seismic signal produced by the failure. The volume of the events is calculated from the amplitude of the signal. The power law fits the volume distribution, with $b=1$. This inventory, obtained from instrumental measurements, tends to show that the power-law behaviour is not a measurement artifact.

All these observations argue for the hypothesis that the power-law distribution well represents the rock fall volume distribution.

For all cases reported in Table 1, the $b$ values show little variation. In particular, they are very close together for studies in the volume range $10-10^{6} \mathrm{~m}^{3}$, varying from 0.41 to 0.46 on natural cliffs. The comparison is interesting for the Grenoble and Yosemite inventories since they are based on the same scale of study - about $100 \mathrm{~km}$ of linear cliff for about 70 years. From a geologist's point of view, it is a priori surprising that the two areas present a similar rock fall distribution shape (power law with similar $b$ value), because the fracturing patterns are fairly different for the two series of cliffs. However, the overall morphological patterns can be considered as similar, with high steep cliffs made of strong rock matrices. This suggests that the discontinuity patterns do not influence the $b$ value of the volume distribution at this scale of study. At a lower scale - a few kilometers - Hungr et al. (1999) propose a higher value for more jointed rock $(b=0.65-0.70)$ than for massive rock $(b=0.40-0.43)$. The Arly study does not confirm this observation. The $b$ value of 0.45 characterizes closely jointed metamorphic and sedimentary rocks. Altogether, for the $10-10^{6} \mathrm{~m}^{3}$ volume range, $b$ is roughly stable, i.e. close to 0.45 .

For smaller rock fall sizes, discussing the $b$ value is still difficult due to the censoring effect observed on most inventories. The only available data set for volumes under $10 \mathrm{~m}^{3}$ 
Table 3. Number per year $\mathrm{n}$ and return period $\mathrm{T}$ calculated for a rock fall with a volume larger than $\mathrm{V}=10^{7} \mathrm{~m}^{3}$, representative of the biggest historical rock falls reported in the Grenoble area in the last centuries. Sensibility to variations in $\alpha$ and $b$ values

\begin{tabular}{|c|c|c|c|c|c|}
\hline & & $\mathrm{b}$ & $\alpha$ & $\begin{array}{c}\mathrm{N} \\
(1 / \text { years })\end{array}$ & $\begin{array}{l}\mathrm{T}=1 / \mathrm{n} \\
\text { (years) }\end{array}$ \\
\hline & $\begin{array}{l}\text { Values calculated from the Grenoble } \\
\text { inventory. }\end{array}$ & 0.41 & 4.2 & $5.6610^{-3}$ & 176 \\
\hline \multirow{3}{*}{$\begin{array}{l}\text { Sensibility } \\
\text { to } \alpha \\
\text { variations }\end{array}$} & $\alpha$ twice as high & 0.41 & 8 & $1.0810^{-2}$ & 93 \\
\hline & $\begin{array}{l}\alpha \text { calculated from the Yosemite } \\
\text { Valley }\left(=18^{*} \text { for } 30 \mathrm{~km}^{2 *}\right) \\
\text { extrapolated to the surface of cliff in } \\
\text { the Grenoble area }\left(24 \mathrm{~km}^{2}\right) .\end{array}$ & 0.41 & 14.4 & $1.9410^{-2}$ & 51 \\
\hline & $\begin{array}{l}\alpha \text { calculated from the Arly gorges } \\
\left(=8.5 \text { for } 0.55 \mathrm{~km}^{2 *}\right) \text { extrapolated } \\
\text { the surface of cliff in the Grenoble } \\
\text { area. }\end{array}$ & 0.41 & 510 & 0.688 & 1.45 \\
\hline \multirow{3}{*}{$\begin{array}{l}\text { Sensibility } \\
\text { to b } \\
\text { variations }\end{array}$} & $\begin{array}{l}\text { b- } 0.5 \text {, minimum value in the error } \\
\text { bar }\end{array}$ & 0.36 & 4.2 & $1.2710^{-2}$ & 79 \\
\hline & $\begin{array}{l}\mathrm{b}+0.5 \text {, maximum value in the error } \\
\text { bar }\end{array}$ & 0.46 & 4.2 & $2.5310^{-3}$ & 395 \\
\hline & $\begin{array}{l}\text { b typical for landslide distributions } \\
\text { (Dussauge et al., 2001) }\end{array}$ & 0.7 & 4.2 & $5.2910^{-5}$ & 18912 \\
\hline
\end{tabular}

* See Table 2.

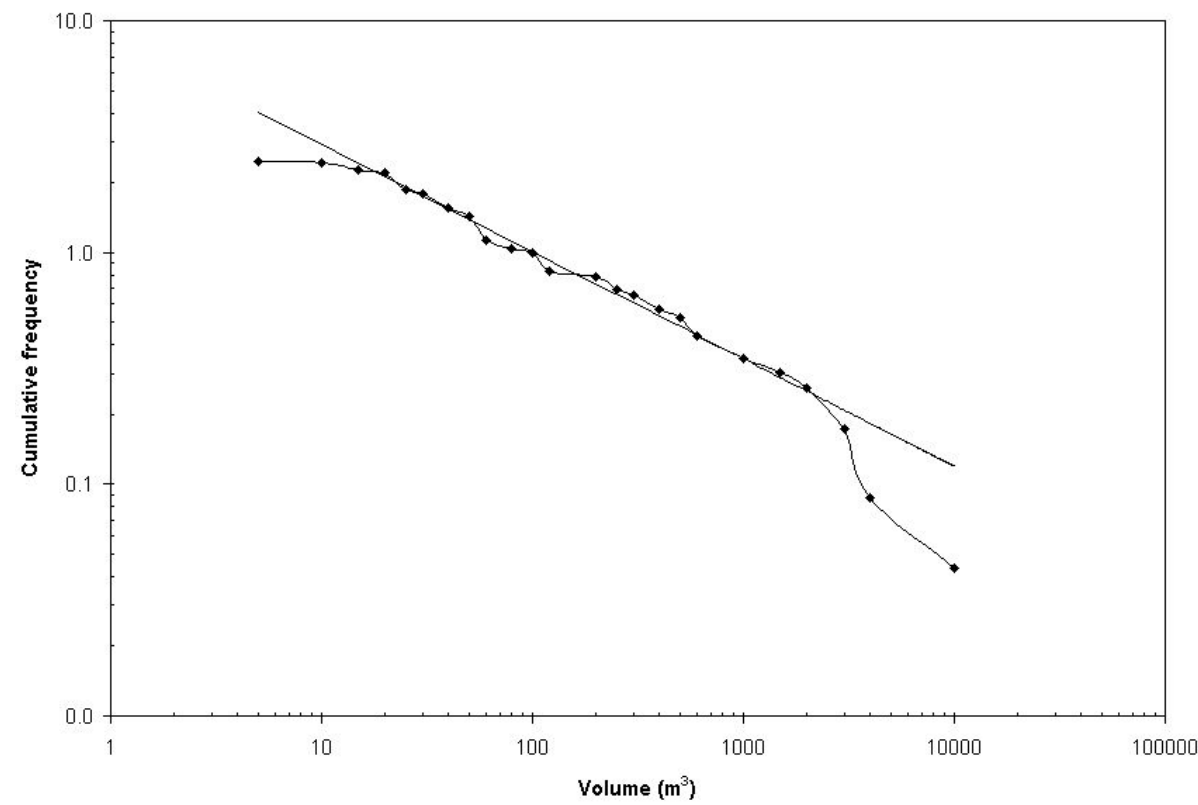

Fig. 5. Cumulative frequency distribution for the rock fall volumes from the upper Arly gorges, France -59 events recorded over $2.2 \mathrm{~km}$ between 1954 and 1976. The straight line represents the power-law fit, with the equation $f=8.5 \mathrm{~V}^{-0.45}$ over the $20-3000 \mathrm{~m}^{3}$ volume range.

is characterized by a $b$ value of 0.72 , which is in the upper range of the $b$ values reported for rock fall volumes (Gardner, 1970; Hungr et al., 1999). Assuming that this value is representative, two hypotheses are possible. On the one hand, it could be inferred that "small" and "big" phenomena do not behave in the same way. The "skin effect", which affects the surface of rock slopes through temperature or thaw cy- cles, could influence the distribution of shallow phenomena, whereas deeper phenomena are more driven by geometrical and mechanical parameters (fracture system, friction angle). On the other hand, the under-sampling of small volumes in the three inventories from Grenoble, Yosemite and Arly could lead to an underestimation of the overall $b$ value, as recently proposed by Stark and Hovius (2001) for landslides. 
At this stage of analyis, more data are required to carry out detailed statistical studies on various volume ranges.

The unique available data set built on instrumental measurements (Rousseau, 1999) provides us with a higher value, with $b=1$. This may be due to the seismic model used for the derivation of the rock fall volumes, based on the amplitude of the seismic signal associated with the failure of a rock mass. This question is presently under investigation.

The $\alpha$ coefficient, as defined in Eq. (1), represents the annual number of events larger than $1 \mathrm{~m}^{3}$. Since such a small volume is not fitted by the power law, it makes no sense to discuss this value in a first step. On the contrary, all three power laws fit the data for a volume $V=100 \mathrm{~m}^{3}$. We define $n_{100}$ as the annual number of rock falls larger than $100 \mathrm{~m}^{3}$. With this definition, $\alpha$ is also $n_{1}$. The values obtained from the three areas studied are reported in Table 2 . In order to compare them on a homogeneous basis, each $n_{100}$ coefficient is divided by the surface of cliffs that are potential sources of rock falls in the area. This surface is roughly estimated, using the total length and approximate mean height.

Contrary to the $b$ values, the normalized $n_{100}$ coefficients fluctuate from one site to another, within at least two orders of magnitude. According to the distribution laws, a $10 \mathrm{~km}^{2}$ surface produces 0.26 events larger than $100 \mathrm{~m}^{3}$ per year in the Grenoble area, 0.72 in the Yosemite Valley. The corresponding value extrapolated from the Arly gorges is 19.45.

\section{Implications for rock fall hazard assessment}

\subsection{Principle of a statistical analysis of historical data}

Statistical analysis of past rock falls can provide a tool for quantifying future hazard in a probabilistic way. Dealing with a data set of events, the procedure to be followed can be divided into three steps.

1. The first step is to establish the volume distribution of the historical data. In order to work on a homogeneous temporal basis, we must select time windows where the rate of activity is almost constant. Statistical tests help to assess whether the distribution fits a mathematical law or not, at least over a certain range of volumes and a certain time window - for example, the $\chi^{2}$ test (e.g. Press et al., 1992).

2. If the data do not fit any law, the inventory can be used to estimate an overall frequency for events with a volume included in the volume range covered by the data (Fig. 6a). Assuming that the distribution is stationary in time, the observed distribution can be used for hazard assessment. No extrapolation is possible for volumes smaller or larger than those already observed.

3. If a law is accepted over a given range of volumes (for example, a power law), the parameters of the distribution can be calculated using a graphic method or a maximum likelihood method. The standard deviation of the values can also be estimated using a maximum likelihood method, and this allows for an error bar to be estimated for future previsions. In the case of a power law, the $\alpha$ coefficient quantifies the level of activity of the area, i.e. the production of rock falls from whole cliffs in the area. However, if the power law does not fit the data down to $1 \mathrm{~m}^{3}$, as often observed, the correct coefficient to be taken into account is $n\left(V_{0}\right)$, the annual number of events larger than $V_{0}$, where $V_{0}$ is the minimum volume fitted by the law.

A distribution law fitting the data is useful at least in two ways. First, within the volume range of historical observation, the calculation of an annual number of events of a given volume (or larger than a given volume) provides a mean value which is less influenced by the statistical fluctuations inherent to observations on a short time window (Fig. 6b). Second, the law provides the possibility to extrapolate the observed distribution for smaller or larger volumes.

The number of events per year $n(V)$ can also be expressed as a return period $\mathrm{T}(\mathrm{V})$, with

$T(V)=1 / n(V)$.

Note that a return period $T(V)=25$ years does not properly mean that an event larger than $\mathrm{V}$ occurs every 25 years, it is only an average over long periods - for example four events in a century.

\subsection{Universal power-law distribution of rock fall volumes?}

Several authors have already proposed that the volume distribution of rock falls is fitted by a power law (Hungr et al., 1999; Wieczorek et al., 1992; Dussauge et al., 2001). Our synthesis gives evidence that the exponent of this law may be site independent. This hypothesis is still difficult to assess with accuracy, since few data sets are available. However, if it can be proven true - through future studies of other inventories - it would provide an interesting tool for assessing rock fall hazards, when coupled with a discussion about the $\alpha$ coefficient.

Indeed, a power law with a constant $b$ value would work as an equivalent for the earthquake size distribution (e.g. Gutenberg and Richter, 1949). The observed earthquake sizes fit the law

$N(M)=\alpha M^{-b}$,

where $M$ is the seismic moment (measuring the energy of an earthquake) and $N(M)$ is the number of earthquakes of a seismic moment larger than $M$. Among others, Main (1996) argues for the stationarity of this law, that is to say the statistical properties of the earthquake frequency-size distribution remain constant in time. In addition, since the earthquake inventories are instrumental, they are considered complete, at least above a given size (resolution level). The parameter $\alpha$ is thus known. It characterises the seismic activity of the area studied, or the long-term seismic moment release rate (Main, 1996). These two arguments justify that this law is currently 
(a)

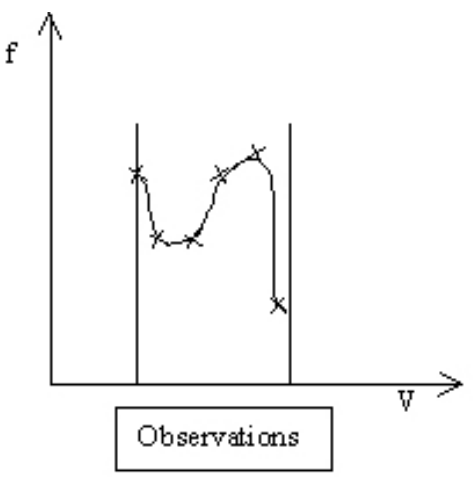

(b)

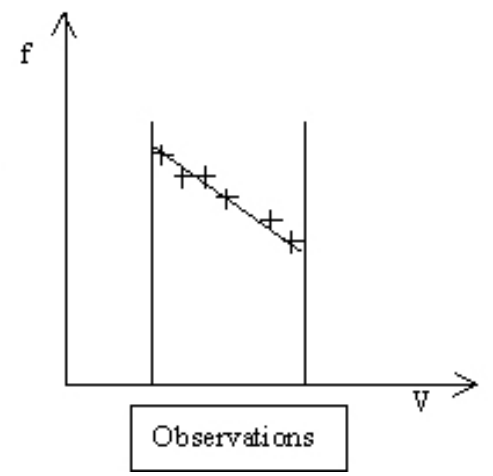

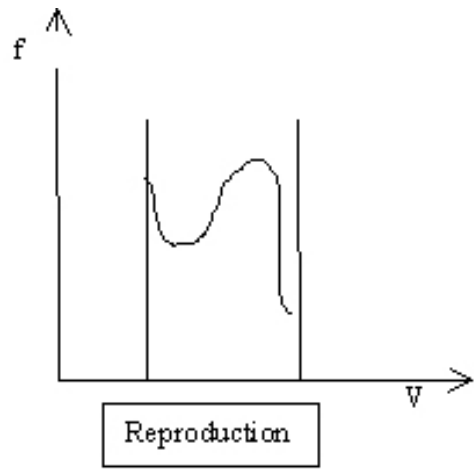

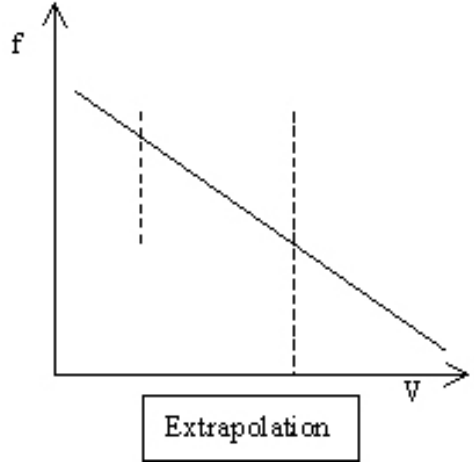

Fig. 6. Schematic representation of possible uses of historical data sets. (a) When the data do not fit any distribution law, the only possibility is to reproduce the distribution over the same volume range. (b) When a power law (or another kind of law) is accepted, the estimation of rock fall frequencies is improved and the distribution can be extrapolated outside the volume range (and time window).

used to derive the future occurrence rate of earthquakes of a given magnitude from past short-term instrumental inventories (e.g. Reiter, 1991).

Drawing a tight parallel to this approach, the power-law distribution of rock fall volumes discussed in Sect. 3 raises important questions. First, is the distribution law stationary over time? Available inventories are not long enough to analyse the temporal variability of the rock fall volume distribution. Wasowski and Del Gaudio (2000) suggested that probabilistic temporal hazard estimates of slope failures can be possible provided that the interval for data completeness is much longer than the event recurrence period. However, the rock fall activity may depend on the loading conditions, including climate or triggering by earthquakes. This may lead to temporal fluctuations of the rock fall activity, and possibly of the $b$ value. Lateltin et al. (1997) point out a relationship between climate change and landslide activity in Switzerland for rather shallow phenomena, whereas deeper phenomena seem to be little influenced (Noverraz et al., 1998). A positive answer to the question about stationarity would validate the calculation of a recurrence rate of future events of a given size on the basis of the occurrence of past events.

Second, is the $b$ value site independent? In the examples studied, the distribution law does not seem to depend on the site considered. For the same range of volumes, the $b$ values are similar regardless of the geological settings - limestone and marls in the Grenoble area, granite in the Yosemite Val- ley, metamorphic rocks in the Arly gorges, felsic rocks in British Columbia (Table 1). On the other hand, the $b$ values reported in various regions for the distribution of landslides in soil materials only are generally higher than $0.6-0.8$ (when recalculated on the basis of homogeneous criteria, i.e. cumulative distribution of volumes of moving material, as described in Dussauge et al., 2001 and references therein). One hypothesis to explain these observations is that the control parameter for the slope movements is the overall strength of the material. This is in accordance with the erosion model proposed by Densmore et al. (1998). The $b$ value of the distribution law of the slope movements involved in erosion processes increases when the geomechanical properties of the slope $-c, \phi-$ decrease. More rock fall and landslide data sets, in regions with various homogeneous geomechanical features, will help to enforce this hypothesis.

Third, how can we compare the rock fall activity for different sites or for different spatial scales? As an example, the spatial distribution of the rock falls in the Arly gorges is not uniform (Fig. 3). The rock fall activity is primarily concentrated in a narrow corridor. Therefore, the rock fall activity, measured as the $\alpha$ coefficient in Eq. (1), for the most active area, cannot be extrapolated for all of the Arly gorges. This extrapolation would induce an overestimation of the rock fall hazard.

Hazard estimate at small spatial scales is not representative of the rock fall activity at larger scales. Indeed, the $\alpha$ value in 
the Arly gorges is far higher than those for the Grenoble area and Yosemite Valley. If we extrapolate the activity for the upper Arly gorges - rock falls concentrated on $0.55 \mathrm{~km}^{2}-$ to the surface of the Grenoble area - approximately $24 \mathrm{~km}^{2}$, we should observe 47 rock falls per year of volume larger than $100 \mathrm{~m}^{3}$ instead of the 0.6 events per year recorded for the Grenoble catalogue (Table 2).

In conclusion, trends are already emerging for the existence of a power law representing the rock fall volume distributions. The $b$ value seems to be site independent for areas with similar rock material properties $-b=0.46 \pm 0.06$, except for the studies from Rousseau (1999) and Hungr et al. (1999) (Table 1) - whereas the $\alpha$ coefficient is spatially variable over several orders of magnitude. The important question is how to isolate homogeneous areas regarding $\alpha$ and $b$. We suggest investigating a possible correlation between the $\alpha$ and $b$ parameters and the geological, geomechanical morphological and climatic settings. It would then become conceivable to estimate rock fall frequencies where no inventory is available.

\subsection{Extrapolation possibilities}

At the present stage, for a given site, we can extract from historical data sets some information on rock fall patterns in the size, space, and time domains implied in the observation. One century of complete observations can be used to propose the expected values for the next century, for the same area and the same range of rock fall volumes. In addition, in terms of hazard analysis, the $10^{2}$ to $10^{6} \mathrm{~m}^{3}$ range of volumes is of particular interest to risk managers dealing with land use at medium or long-time scales, i.e. a few years to a few decades - small block falls cause many accidents but are dealt with at a short time scale, i.e. a few months (e.g. Interreg IIc, 2001). This range is actually the one best fitted by a power law and probably the most completely reported. For example, in the Grenoble area, the distribution allows us to expect a decennial event of $10^{4} \mathrm{~m}^{3}$, or an average of four $10^{5} \mathrm{~m}^{3}$ events within a century.

The extrapolation of this law to small volumes is still delicate due to sampling resolution, as already discussed. On the other extreme, the extrapolation to larger volumes must be handled carefully. As shown in Table 3, it is very sensitive to the $\alpha$ and $b$ values chosen for the power law. Such extrapolations are only feasible when the limits of the inventory used are very well defined, i.e. statistical tests certify its completeness, and $\alpha$ and $b$ are well constrained. However, even if the error bars are large, extrapolated recurrence rates can be estimated. It would not be possible without the existence of a distribution law. For our study, a first indicator for the robustness of the law is given by the existence of a power law with similar $b$ values for data collected over different volume ranges, space scales and period lengths: $0.01-10 \mathrm{~m}^{3}$, a few hundreds of $\mathrm{m}^{2}$ and 2 summer periods in Alberta (Gardner, 1970; Hungr et al., 1999), 50-106 $\mathrm{m}^{3}, 30 \mathrm{~km}^{2}$ and 80 years in Yosemite (Wieczorek et al., 1992; Dussauge et al., 2001).
These observations validate the extrapolation of the rock fall volume distribution to volumes larger than the available data.

\subsection{Hazard assessment}

As requested by risk managers, evaluating rock fall hazard includes estimating the probability of failure of identified rock masses within a given period of time. Our study shows that statistical studies of past events provide a tool for quantifying an overall frequency of rock falls on a given area (at the scale of a whole cliff or series of cliffs). This is not yet the probability of occurrence of a specific instability. As a parallel, data sets of historical seismicity help to estimate the probability of occurrence of an earthquake of a given magnitude, but not predicting exactly where it will occur (frequency of events). The statistical spatial distribution of the events associated with a propagation law (attenuation of the horizontal ground acceleration with the distance) is the basis for building probabilistic seismic hazard maps (e.g. Dominique et al., 1998; Romeo et Pugliese, 1998). On the other hand, pointing out the locations most susceptible for a rock failure is local field work (at the scale of specific rock masses), based on geological and geomechanical considerations, which leads to characterization of potential instabilities. The crossing of these two approaches aims at estimating the individual probability of failure for a specific instability, which is the final goal of such a process (Vengeon et al., 2001).

\section{Conclusion}

The observation of several rock fall inventories shows that a power-law distribution (Eq. (1)) fits the data for a given range of volumes. For various types of rock cliffs, the $b$ values are similar -0.41 to 0.46 - whereas the $\alpha$ values (more precesely $n_{100} / 10 \mathrm{~km}^{2}$ ) vary within at least two orders of magnitude. The existence of such a law provides interesting opportunities for a probabilistic assessment of rock fall hazards. First, the application of the distribution law improves the estimation of a mean recurrence rate for events in the volume range of the reported data. The fluctuation of the values observed in short-time windows are smoothed. Second, it gives the possibility to extrapolate the distribution for large events that are not reported in the observed period.

However, considering the relatively high standard deviation of the $b$ values (close to $0.1-0.15$ for Grenoble, Yosemite and val d'Arly, respectively), and the sensibility of the return period estimates to the variations of the $b$ value, one may argue on the practical accuracy for hazard assessment. It is important to constrain correctly the parameters before any extensive use of this law for hazard assessment. Further investigation on various inventories is still required to confirm the site independence of the $b$ value. Systematic comparison between the rock fall activity (frequency of events) and the characteristics of the source area - geological, geomechanical and morphological settings of the rock mass, climatic conditions - will help to constrain the $\alpha$ parameter. 
Acknowledgements. We gratefully thank P. Desvarreux and the S.A.G.E engineering office, J.P. Requillard and the R.T.M. office, and G. Wieczorek, who made the data available for the three inventories we used in this study, respectively Arly gorges, Grenoble area and Yosemite Valley. Comments by G. Wieczorek and review by G.B. Crosta and J. Wasowski improved the quality of the manuscript. J.M. Vengeon is acknowledged for his useful discussions.

\section{References}

Aki, K.: Maximum likelihood estimation of $\mathrm{b}$ in the formula $\log (N)=a-b M$ and its confidence limits, Bull. Earthquake Res. Inst., Tokyo Univ., 43, 237-239, 1965.

Azimi, C. and Desvarreux, P.: Quelques aspects de la prévision des mouvements des terrain, Revue française de géotechnique, 76, 63-75, 1996.

Blodgett, T. A., Isacks, B. L., Fielding, E. J., Masek, J. G., and Warner, A. S.: Erosion attibuted to landslides in the Cordillera Real, Bolivia, Eos Trans. AGU, 17, 17, Spring Meet. Suppl. S261, 1996.

Cancelli, A. and Crosta, G.: Rockfall hazard in Italy: assessment, mitigation and control, in Environment management, geo-water and engineering aspects, Balkema, Wollongong, 1993.

Densmore, A., Ellis, M., and Anderson, R.: Landsliding and the evolution of normal-fault-bounded mountains, J. Geophys. Res., 103, 7, 203-219, 1998.

Dominique, P., Autran, A., Blès, J. L., Samarcq, F., and Terrier, M.: Probabilistic approach: seismic hazard map on the national territory (France), in 11th Eur. Conf. on Earthquake Engineering, Balkema, Paris, 1998.

Dussauge, C., Grasso, J. R., and Helmstetter, A.: Statistical analysis of rock falls: implication for hazard assessment and underlying physical processes, J. Geophys. Res, submitted, 2001.

Erisman, T. H. and Abele, G.: Dynamics of rockslides and rockfalls, Springer, 2001.

Gardner, J.: Rockfall: a geomorphic process in high mountain terrain, The Albertan Geographer, 6, 15-20, 1970.

Guillot, P. and Duband, R.: La méthode du GRADEX pour le calcul de probabilité de crues à partir des pluies, IASH Publication (84), 1967.

Gutenberg, B. and Richter, F.: Seismicity of the earth and associated phenomena, Princeton Univ. Press, Princeton, N. J., 1949.

Hoek, E.: Analysis of rock fall hazards, in Rock Engineering, Course notes; Chapter 9; http://www.rockeng.utoronto.ca/ hoekcorner.htm, 115-136, 1998.

Hovius, N., Stark, C. P., and Allen, P. A.: Sediment flux from a mountain belt derived by landslide mapping, Geology, 25, 3, 231-234, 1997.

Hungr, O., Evans, S. G., and Hazzard, J.: Magnitude and frequency of rock falls along the main transportation corridors of southwestern British Columbia, Canadian Geotechnical Journal, 36, 224-238, 1999.

Interreg IIc: Prévention des mouvements de versants et des instabilités de falaise - Groupe falaise - Confrontation des méthodes d'étude des éboulements rocheux dans l'arc alpin, Programme Interreg IIc, Mditerranée occidentale et Alpes Latines, 2001.

Jeannin, M.: Approches quantitatives de l'érosion des versants rocheux. Etude des gorges de l'Arly et du sillon subalpin. DEA report, Lirigm, Univ. Joseph Fourier, Grenoble, 2001.
Lateltin, O., Beer, C., Raetzo, H., and Caron, C.: Instabilités de pente en terrain de flysch et changements climatiques. Rapport final PNR 31, 168, Zürich, 1997.

Luckman, B. H.: Rockfalls and rock fall inventory data: some observations from Surprise Valley, Jasper National Park, Canada, Earth Surface Processes, 1, 287-298, 1976.

Main, I.: Statistical Physics, seismogenesis and seismic hazard, Reviews of Geophysics, 34, 4, 433-462, 1996.

Mazzoccola, D. and Sciesa, E.: Implementation and comparison of different methods for rock fall hazard assessment in the Italian Alps, in 8th Int. Symp. on Landslides, 1035-1040, Cardiff, UK, 2000.

Noverraz, F., Bonnard, C., Dupraz, H., and Huguenin, L.: Grands glissements de versants et climat, VERSINCLIM: Comportement passé, présent et futur des grands versants instables subactifs en fonction de l'évolution climatique, et évolution en continu des mouvements en profondeur. Rapport final PNR 31, 314, Zürich, 1998.

Press, W. H., Teukolsky, S. A., Vettering, W. T., and Flannery, B. P.: Numerical recipes in C, Cambridge Univ. Press, 994, Cambridge, 1992.

Reiter, L.: Earthquake hazard analysis, Columbia Univ. Press, New York, 1991.

Romeo, R. and Pugliese, A.: A global earthquake hazard assessment of Italy, in 11th Eur. Conf. on Earthquake Engineering, Balkema, Paris, 1998.

Rouiller, J. D., Jaboyedoff, M., Marro, C., Philippossian, F., and Mamin, M.: Pentes instables dans le Pennique valaisan, MATTEROCK: une méthodologie d'auscultation des falaises et de détection des éboulements majeurs potentiels, Rapport final PNR 31, edited by vdf Hochschulverlag AG an der ETH, 239, Zürich, 1998.

Rousseau, N.: Study of seismic signals associated with rockfalls at 2 sites on the Reunion island (Mahavel Cascade and Souffrière cavity), PhD Thesis, IPG, Paris, 1999.

RTM Isère: Inventaire des mouvements rocheux, Secteur de l'Y grenoblois, Service de Restauration des terrains en Montagne de l'Isère, Grenoble, France, 1996.

Stark, C. P. and Hovius, N.: The characterisation of landslides size distributions, Geophys. Res. lett., 26, 6, 1091-1094, 2001.

Vengeon, J. M., Hantz, D., and Dussauge, C.: Predictabilité des éboulements rocheux: approche probabiliste par combinaison d'études historiques et géomécaniques, Revue Francaise Geotechnique, 95-96, 1, 2001.

Wasowski, J. and Del Gaudio, V.: Evaluating seismically induced mass movement hazard in Caranico Terme (Italy), Eng. Geol., 58, 291-311, 2000.

Water Resources Council: Guidelines for determining flood flow frequency, Bulletin 17B: Hydrology subcommitee, Office of Water Data Coordination, US Geological Survey, Reston, VA, 182, 1982.

Wieczorek, G. and Jäger, S.: Triggering mechanisms and depositional rates of postglacial slope movement processes in the Yosemite Valley, California, Geomorphology, 15, 17-31, 1996.

Wieczorek, G., Nishenko, S. P., and Varnes, D. J.: Analysis of rock falls in the Yosemite Valley, California, in 35th US Symposium on Rock Mechanics, edited by J. J. Daemen, and Schultz, R. A, 85-89, A. A. Balkema, Daemen, 1995.

Wieczorek, G. F., Snyder, J. B., Alger, C. S., and Isaacson, K. A.: Yosemite historical rockfall inventory, US Geol. Surv. Open File Report, 92-387, 38, 1992. 